\title{
Development of building blocks using vegetable oil and recycled aggregate
}

\author{
Mohamed I. Attia ${ }^{1}$, Salah Zoorob ${ }^{2}$, Khaled Hassan ${ }^{1 *}$, Hozaifa El-husseini ${ }^{1}$, James M. \\ Reid $^{2}$ and Mohamed S. Al kuwari ${ }^{3}$ \\ ${ }^{1}$ TRL-QSTP-B, Qatar Science and Technology Park, Qatar. \\ ${ }^{2}$ TRL, Crowthorne House, Nine Mile Ride, Crowthorne, Berkshire, UK. \\ ${ }^{3}$ Ministry of Municipality and Environment, Qatar.
}

\begin{abstract}
The primary objective of this research was to contribute towards greater sustainability of the construction industry in the Qatar by proposing methods to reduce its dependency on primary imported materials. In this investigation, recycled and secondary aggregates (RSA) were combined with non-traditional binders to develop a unique method of manufacturing construction and building blocks. Following an extensive phase of laboratory trials and experimentation, it was realised that many types of graded mineral aggregates, when mixed with vegetable oils (virgin or waste) at optimal proportions, then compacted and thermally cured at elevated temperatures can readily generate hardened composites that have the mechanical characteristics of conventional building blocks. The resultant blocks have been named "Vegeblocks" and are viewed as viable alternatives to conventional concrete blocks. Furthermore, the research has demonstrated the feasibility of producing Vegeblocks composed of $100 \%$ recycled aggregate and discarded waste cooking oil. Based on physical and mineralogical properties, each type of aggregate has an optimum oil content for maximum compressive strength, beyond which, any additional oil will result in reduction in mechanical properties. Acceptable compressive strength values were achieved by thermally curing Vegeblocks at of $170^{\circ} \mathrm{C}$ for 24 hours.
\end{abstract}

\section{Introduction}

Qatar has limited supply of high quality aggregate and the construction industry depends heavily on imported gabbro [1]. Ongoing research in Qatar focused on evaluating the suitability of exploiting recycled and secondary aggregate (RSA) in various construction applications including concrete, concrete blocks, and granular subbase for roads $[1,2]$.

The concept of utilizing alternative binders to Portland cement for construction blocks has the advantages of reducing costs with more impact on the environment. Lutfi presented a patent for using vegetable oil as a binding agent for construction material and for soil stabilization [3]. In 2006 a team of researchers from Leeds and Nottingham Universities

\footnotetext{
* Corresponding author: khassan@trl.co.uk
} 
continued the research on using vegetable oils as binders in the development of building blocks, and named this class of product Vegeblocks [4, 5]. It was reported that vegetable oil could be mixed with aggregates at ambient temperatures to produce a workable, compactable product, which when thermally cured produced an oxy-polymerized composite of high strength named Vegeblock. This work was later presented in a patent [6].

Forth and Zoorob's patent [6] focused on curing the mixed aggregate and oil in an oven, resulting in oxidation of the vegetable oil, which in turn caused a significant increase in block strength. One of the main differences between the two patents is that Forth and Zoorob [6] focused on curing the Vegeblock sample after extraction from the compaction mould, while Lutfi [3] proposed curing the sample whilst still in the mould. Further details on possible oxy-polymerization processes that take effect in vegetable oil and cause it to harden and act as a rigid binding agent was presented in $[5,7]$.

\section{Objectives}

The aims of the research were to improve the sustainability of the construction industry in Qatar by reducing $\mathrm{CO}_{2}$ emissions from manufacture of cement and import of high quality primary aggregates. The specific objectives were:

- Use non-traditional and environmental friendly binders for developing construction blocks.

- Using recycled and secondary aggregate (RSA) for developing construction blocks.

- Develop an understanding of the factors affecting the strength of the developed blocks.

- Optimize the development of novel building blocks that utilize vegetable oil as the binding agent instead of cement. Furthermore, investigate the potential for using $100 \%$ recycled and secondary aggregate (RSA) in the development of Vegeblocks.

- Evaluate the suitability of producing mid-size blocks based on the optimized formulations as a step towards full scale mechanical production of Vegeblocks.

- Initial evaluation of the effect of direct flame on Vegeblocks.

\section{Experimental program for optimization of vegeblocks production}

\subsection{Materials}

\subsubsection{Aggregate}

- Limestone from excavation waste (EW);

- A blend of EW and incinerator bottom ash (IBA) (50/50 by weight);

- A blend of EW and unwashed sand (50/50 by weight), simply referred to as sand in this paper.

The research focused on using locally available materials in Qatar. Qatar is underlain by geologically young limestone that is highly variable in strength and hence is not used as aggregate for concrete or concrete blocks [1]. There has been a major boom in construction in Qatar over the last decade, with many major infrastructure projects and new buildings ahead of the 2022 World Cup. This has resulted in large quantities of limestone being generated in Qatar during excavation for building and infrastructure construction. Most of this material is dumped in landfills in the desert, though some is now being recycled as aggregate for use in construction [8]. 
IBA is generated from an Energy-from-Waste plant that opened in 2012 to handle municipal waste from Doha, the capital of Qatar. The IBA is stockpiled in a landfill next to the Energy-from-Waste plant. The suitability of this IBA for use in construction was evaluated earlier [1].

In the south west of Qatar the limestone is overlain by occasional deposits of alluvial gravelly sand. This material has been widely exploited for use as fine aggregate in concrete. However, the sand normally has high sulphate and clay contents, so it has to be washed to become acceptable for use in concrete. However, much of the sand has sulphate content that is too high to be treated by current technology. This unwashed sand was used in the trials reported here.

All the aggregates listed above were sieved through a $5 \mathrm{~mm}$ sieve. The gradation of all three aggregate types is presented in Fig 1. Material was classified in accordance with the unified soil classification system (USCS) [9]. EW+sand was found to be poorly graded sand (SP), EW is well graded sand with clay (SW-SC), the EW+IBA was classified as well graded sand, but the liquid limit and plastic limit were not well defined, thus it was not possible to accurately define the type of fines (silty or clay), nonetheless the material lies between (SW-SM and SW-SC).

\subsubsection{Vegetable oil}

Two vegetable oil types were trialled in this investigation, namely virgin palm oil (VPO) and post-consumer or used palm oil (UPO). Palm oil is classified as non-drying oil, with iodine value ranging from 43 to 58. The iodine value is a measure of the average degree of unsaturation of a lipid; the higher the iodine value, the greater the number of $\mathrm{C}=\mathrm{C}$ double bonds and the higher the potential for polymerisation [10]. Non-drying oil does not harden when it is exposed to air at ambient temperatures, though it will oxidize by heating at higher temperatures, and it is readily available in Qatar.

\subsection{Sample preparation}

800 grams of aggregate was mixed manually with a predetermined amount of oil, which was enough to produce three compacted cubes $50 \times 50 \times 50 \mathrm{~mm}$ of each mixture type, as presented in Figure 2. The oil content was defined as a percentage of aggregate weight.

The samples were compacted and tested following ASTM C 109 [11] for 50mm mortar cube specimens. Compaction was conducted manually using a tamping rod, 32 blows each layer for 2 layers. The compacted samples were carefully extruded whilst being kept supported on a flat aluminium base plate and gently transferred into a pre-heated oven whilst resting on the base plates. Curing of compacted samples was carried out in a ventilated oven pre-set to a temperature in the range of 170 to $190{ }^{\circ} \mathrm{C}$.

Fig 2 shows some of the samples prepared during this phase. It shows an example of the change in colour caused by varying the oil contents; as oil content increases, the samples become darker. The experimental programme was conducted in three stages. 


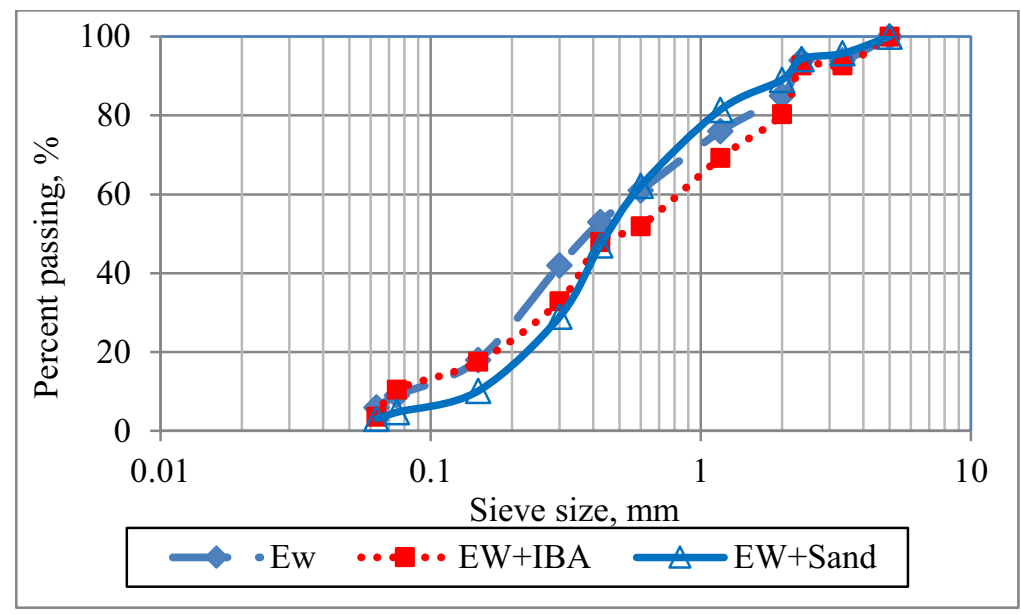

Fig. 1. Gradation of the aggregate materials.

\subsubsection{Stage 1}

Determine the optimum oil content (OOC) for each aggregate and oil type. The remaining variables were held constant at:

- Curing duration: 24 hours

- Curing temperature: $170{ }^{\circ} \mathrm{C}$

This combination of curing duration and temperature had been proven in a preliminary stage of the research to result in acceptable strength for Vegeblocks composed of sand and palm oil. This combination was also reported to be acceptable production parameters for samples composed of limestone and rapeseed oil [5].

Preliminary testing had shown that curing temperatures lower than $160{ }^{\circ} \mathrm{C}$ resulted in samples that were not adequately cured within 24 hours, while temperatures higher than $200{ }^{\circ} \mathrm{C}$ resulted in a reduction in the compressive strength of the cured sample.

\subsubsection{Stage 2}

To understand the effect of curing duration on samples made of recycled materials. For this stage all samples were prepared at the OOC values as defined in stage one. The samples were all cured at $170{ }^{\circ} \mathrm{C}$ for durations of 12,24 and 48 hours. 


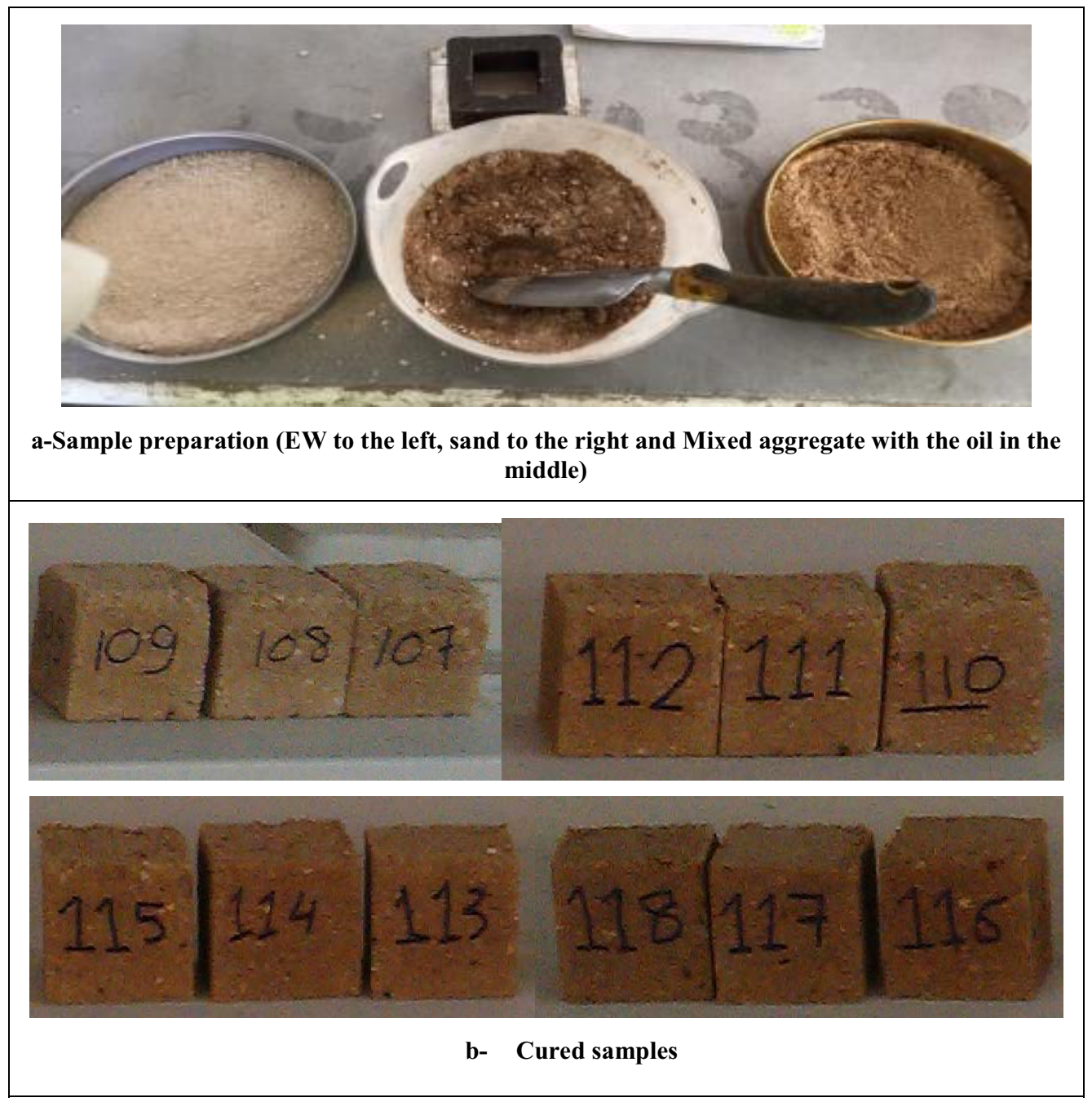

Fig. 2. Samples of Vegeblocks during preparation and after curing.

\subsubsection{Stage 3}

Define an optimum curing temperature. In this stage all samples were prepared at the optimum oil content, and cured for 24 hours. The duration of 24 hours was selected because it was the shortest period where samples started to show a good level of curing and developed the target strength, as will be presented in the results section. The curing temperatures were 170,180 , and $190{ }^{\circ} \mathrm{C}$. Figure 3 presents a summary of the experimental programme.

\subsection{Testing}

There are two main requirements for non-load bearing blocks in Qatar according to the Qatar construction specification (QCS 2014), Section 13, Part 4[12]; mainly compressive strength and water absorption. 
All cubes samples were tested (after curing in the oven) for compressive strength following ASTM C 109 [11], and similarly, density was determined for all samples. The target was to produce non-load bearing blocks that fulfil the QCS 2014 [12] minimum strength requirements of $4.0 \mathrm{MPa}$.

The optimum conditions were defined as the lowest curing temperature and shortest curing duration that achieved the strength requirements at the optimum oil content.

Water absorption was evaluated for samples prepared at optimum conditions. In this test procedure, the dry weight of each sample was first measured, then each test specimen was immersed in water for 30 minutes, and the saturated weight was re-measured in air. This test procedure was according to QCS 2014 [12], test method outlined in [13]. Water absorption is defined in Equation 1:

$$
\% \text { Water Absorption }=\left[\left(W_{s}-W_{d}\right) / W_{d}\right] \times 100
$$

where:

$W_{s}=$ Weight of specimen after immersion in grams (Saturated surface dry);

$W_{d}=$ Dry weight of specimen in grams.

For each material composition and curing condition, at least 3 samples were prepared and tested. All the results presented in this paper are for the average of three samples at each mixing and curing condition. A flowchart of the experimental programme is shown in Fig 3.

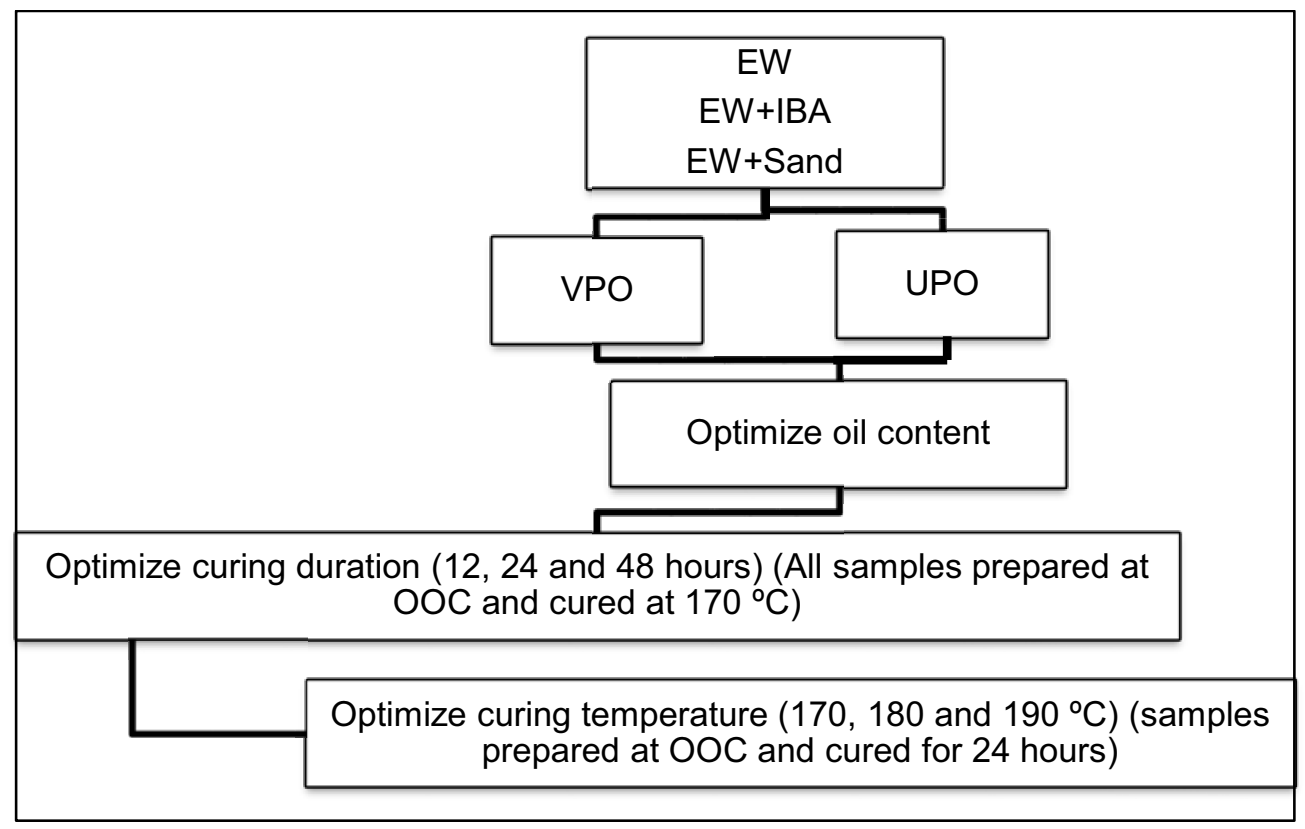

Fig. 3. Overview of optimization experimental programme.

\section{Optimization results and analysis}

\subsection{Effect of oil content and type on compressive strength}

Figure 4 ( $a$ and $b$ ) shows that increasing the oil content improves the strength of the Vegeblock up to a certain limit (optimum), after which the strength begins to decline. The 
aggregate type has a clear effect on the strength of the developed strength. The (EW + IBA) mixture blended with VPO and cured for 24 hours had the lowest compressive strength results, barely achieving the $4.0 \mathrm{MPa}$ minimum strength requirements for non-load bearing blocks. The EW oil blends had acceptable compressive strength results, achieving 5.0 MPa using VPO and 8.0 MPa using UPO. As can be observed from Fig. 4, the highest compressive strength was achieved with the $(\mathrm{EW}+\mathrm{sand})$ mixture.

The results also show that used palm oil gave slightly higher strength compared to the virgin palm oil. This is clearer with the EW mixture exhibiting approximately $35 \%$ higher strength for the used oil neat optimum content. At oil content higher than the optimum both virgin and used oil gave similar results and trends for the different aggregate types.

The optimum oil content values for the evaluated materials are presented in Table 1. EW + IBA had the highest optimum oil content of $16 \%$, this was followed by $12 \%$ for $\mathrm{EW}$, then $\mathrm{EW}+$ sand had OOC of 8 to $10 \%$ depending on oil type. These oil contents are considered high compared to the 5\% oil content used in the earlier research by [5] and the $4 \%$ to $4.5 \%$ OOC obtained in preliminary trials using sand and vegetable oil. This can be attributed to the finer gradation and higher absorption value of RSA compared to the sand used in the earlier trials. EW and IBA also had relatively high fine contents compared to the sand, which would require more oil to coat all the particles with an adequately thick layer of oil that could bind the particles together.

The water absorption values of the raw material are also presented in Table 1. EW+IBA had high water absorption compared to other materials. Higher water absorption of the aggregate may have resulted in higher optimum oil content. This high water absorption would also affect the available oil (effective oil) that can actually bind the particles. The strength gain is dependent on the oil content. Samples with low oil content had low compressive strength. It was possible to break some samples with bare hands after curing at low oil contents (such as 4 and $6 \%$ for EW). These samples were also difficult to handle before heat curing (fragile samples).

It was not possible to test some samples that had high oil content (for example, $16 \%$ oil content for a mixture of sand $+\mathrm{EW}$ ). In these cases, the samples became stuck to the base plates following curing making it impossible to separate the samples from their supports without damaging the sample. It is likely that oil content was too high and resulted in binder drainage from the sample during curing.

Table 1. Optimum oil content for different aggregate types.

\begin{tabular}{|c|c|c|c|}
\hline $\begin{array}{c}\text { Aggregate } \\
\text { type }\end{array}$ & Oil type & $\begin{array}{c}\text { Optimum oil } \\
\text { content }\end{array}$ & $\begin{array}{c}\text { Water absorption of } \\
\text { aggregate (ASTM } \\
\text { C128), \% }\end{array}$ \\
\hline EW & VPO & 12 & 4.70 \\
\hline EW & UPO & 12 & 4.70 \\
\hline EW+IBA & VPO & 16 & 6.50 \\
\hline EW+IBA & UPO & 16 & 6.50 \\
\hline EW+Sand & VPO & 10 & 2.90 \\
\hline EW+Sand & UPO & 8 & 2.90 \\
\hline
\end{tabular}




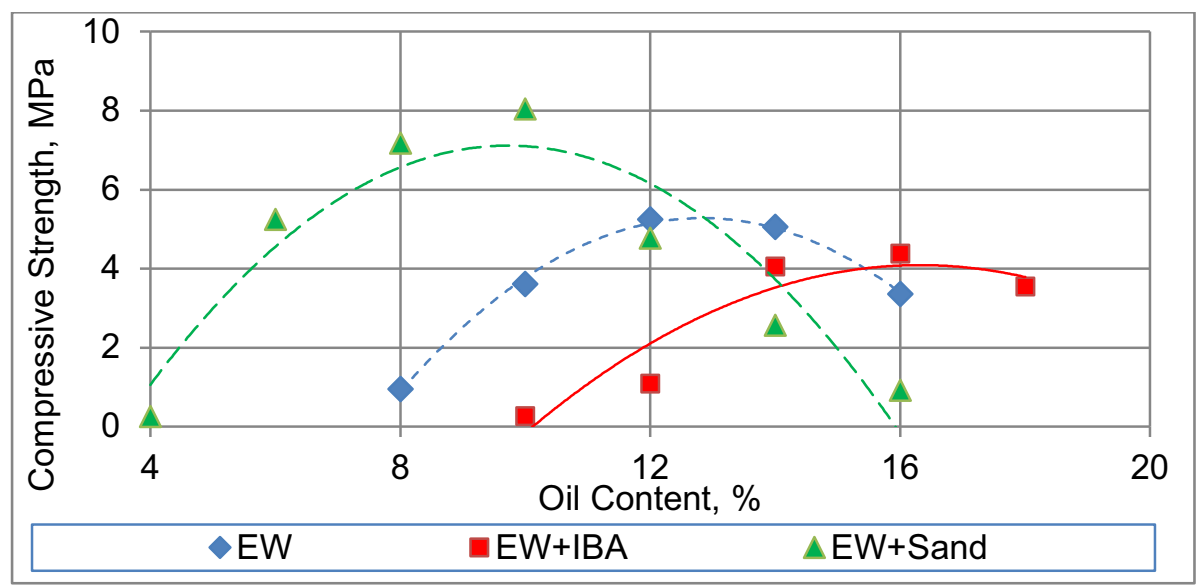

a - RSA aggregate + VPO

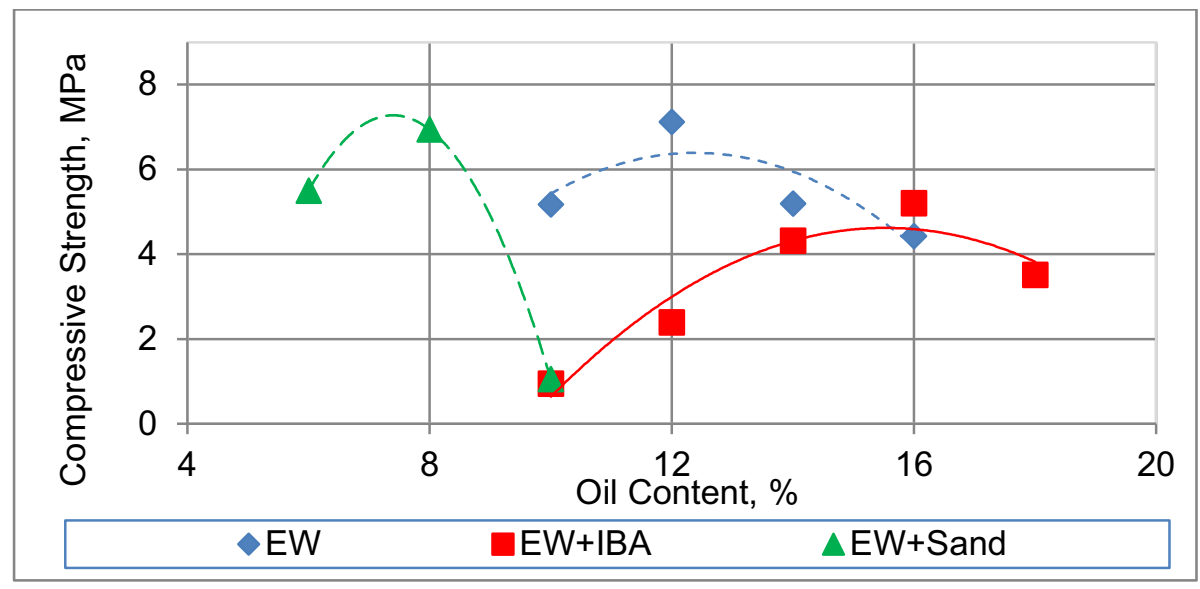

b- RSA aggregate + UPO

Fig. 4. Effect of oil content on compressive strength of RSA aggregate blends.

\subsection{Effect of curing duration on compressive strength}

It is expected that the oxy-polymerization reactions that are dominant during thermal curing of vegetable oils will be time dependent. It is important from an environmental and economic point of view to determine the minimum curing duration necessary to develop the required strength of the Vegeblocks. The effect of curing duration was evaluated at three levels (12, 24 and 48 hours). Compressive strengths for all materials investigated are presented in Fig 5. For all materials, increasing curing duration caused a clear increase in compressive strength. The 12 hour period was too short for curing the samples; as many samples showed a friable bottom at this short period; and after compressive strength testing it could clearly be seen that the core of the sample was not well cured. Comparing the results for 24 to 48 hours indicated improvement in the strength by 4 to $41 \%$ for different materials. The EW + sand with UPO had the lowest improvement in compressive strength when curing duration was extended from 24 to 48 hours, while EW + sand with VPO had the highest. 
It is expected that a longer curing duration can improve the strength; however, the shorter period (24 hours), was adequate for achieving the target compressive strength of 4.0 MPa.

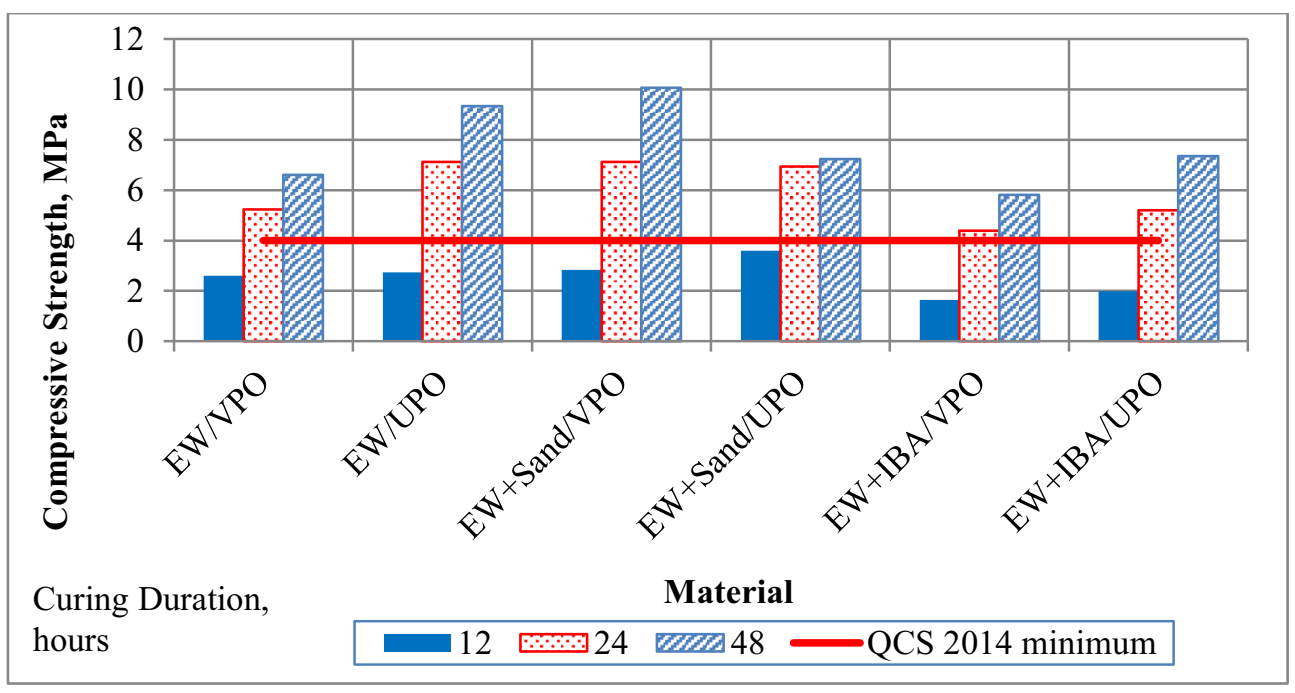

Fig. 5 Effect of curing duration on compressive strength.

\subsection{Effect of curing temperature on compressive strength}

The effect of curing temperature on the strength of Vegeblocks is presented in Fig 6. Increasing the curing temperature from 170 to $190{ }^{\circ} \mathrm{C}$ improved the compressive strength of the various blends by an amount ranging from $27 \%$ up to $58 \%$. The highest strength improvement was achieved for (EW + IBA) mixed with VPO whereas (EW + sand) mixed with UPO exhibited the least improvement in strength. At short times of curing, the higher temperature can result in a faster rate of oxy-polymerization reaction, which in turn will produce a higher compressive strength. The $170^{\circ} \mathrm{C}$ was enough to achieve the target strength with 24 hours of curing.

\subsection{Water absorption}

The water absorption was evaluated for $\mathrm{EW}$ and $\mathrm{EW}+$ sand mixtures only. The EW absorbed $1.5 \%$ while EW + sand absorbed $1.9 \%$ of water. This is far below the QCS 2014 requirement of 7\% maximum water absorption. These values looks small compared to the water absorption of 4 to $11 \%$ reported after 24 hours soaking in water [5]. It is also smaller than particles water absorption reported in Table 1, reflecting that oil had coated the aggregate particles. However, it must be noted that the low water absorption is based on soaking in water for only 30 minutes, which is the current Qatar construction specification requirement [12]. 


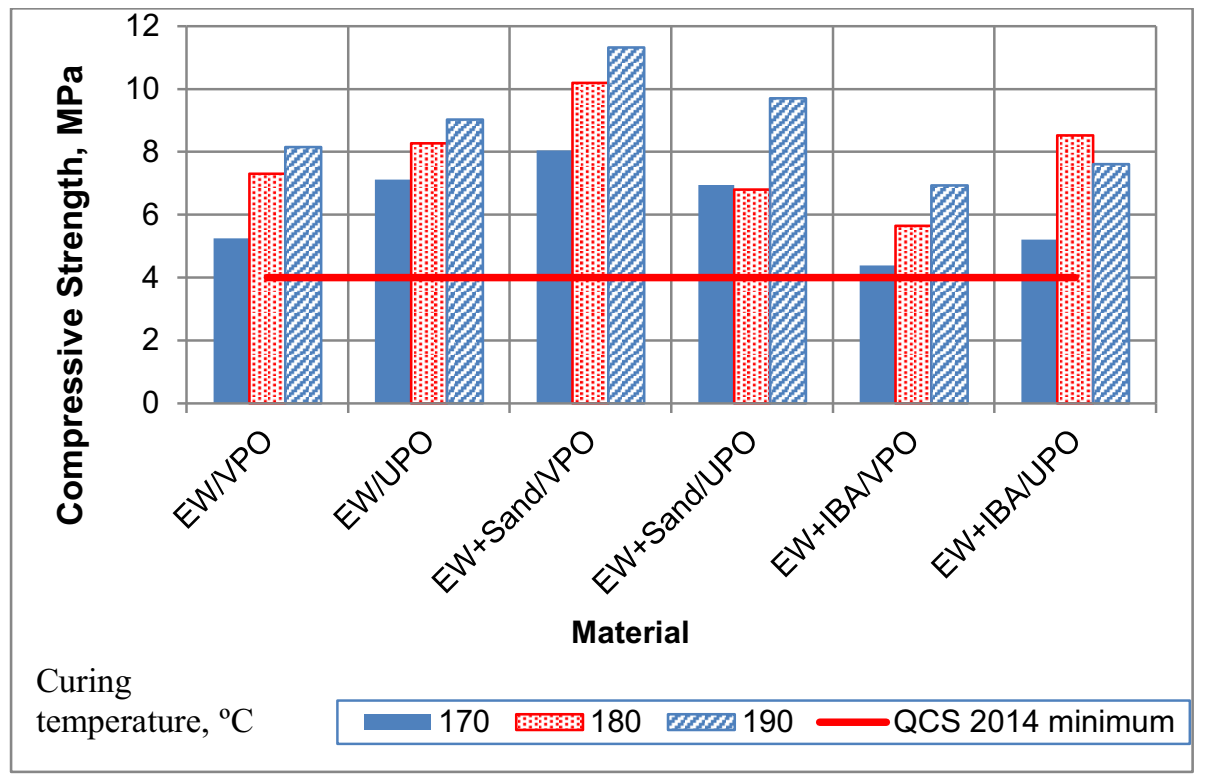

Fig. 6. Effect of curing temperature on compressive strength.

\section{Manual block production (mid-size blocks)}

This step aimed to give a better insight of the suitability of producing real size construction blocks and prove that the Vegeblock concept can be taken further for full scale production. The concern was that the Vegeblock would be too weak while in its green (uncured) condition, to the level that it would not be possible to produce real size construction blocks.

A mould was designed to produce significantly larger sized VegeBlocks than the 50 $\mathrm{mm}$ cubes. The block was designed to be a $200 * 100 * 50 \mathrm{~mm}$ hollow block. The mould and produced block are presented in Fig 7. The height of the block was chosen to be $50 \mathrm{~mm}$ to avoid long walls and to simulate the initial cubes that were manufactured in the previous stage of the research. The thickness of the web was similar to that of regular produced concrete blocks $(40 \mathrm{~mm})$. This thickness was also considered acceptable as it would facilitate the curing process.

The material was poured inside the mould and compacted over two layers. Each layer was subject to 25 hits by the manual compaction tool shown in Fig 7. The compaction process was conducted while the sample was supported by a steel plate underneath it in order to be carried to the oven. After de-moulding the sample, the Vegeblocks were transferred carefully to the oven and cured for 24 hours at $170^{\circ} \mathrm{C}$ (optimum conditions as defined for small cubes).

At this stage samples were prepared at the optimum oil content (OOC) only. Used palm oil (UPO) was used to produce the Vegeblocks. The produced Vegeblocks were made of the following materials:

- Excavation Waste (EW) with OOC of $12 \%$;

- EW+ unwashed sand with OOC of $8 \%$;

- EW+ incinerator bottom ash (IBA), with OOC of $16 \%$.

This experiment proved to be successful, and the Vegeblock were compacted and cured. This presented the first step towards full scale/mechanical production of the Vegeblock. 


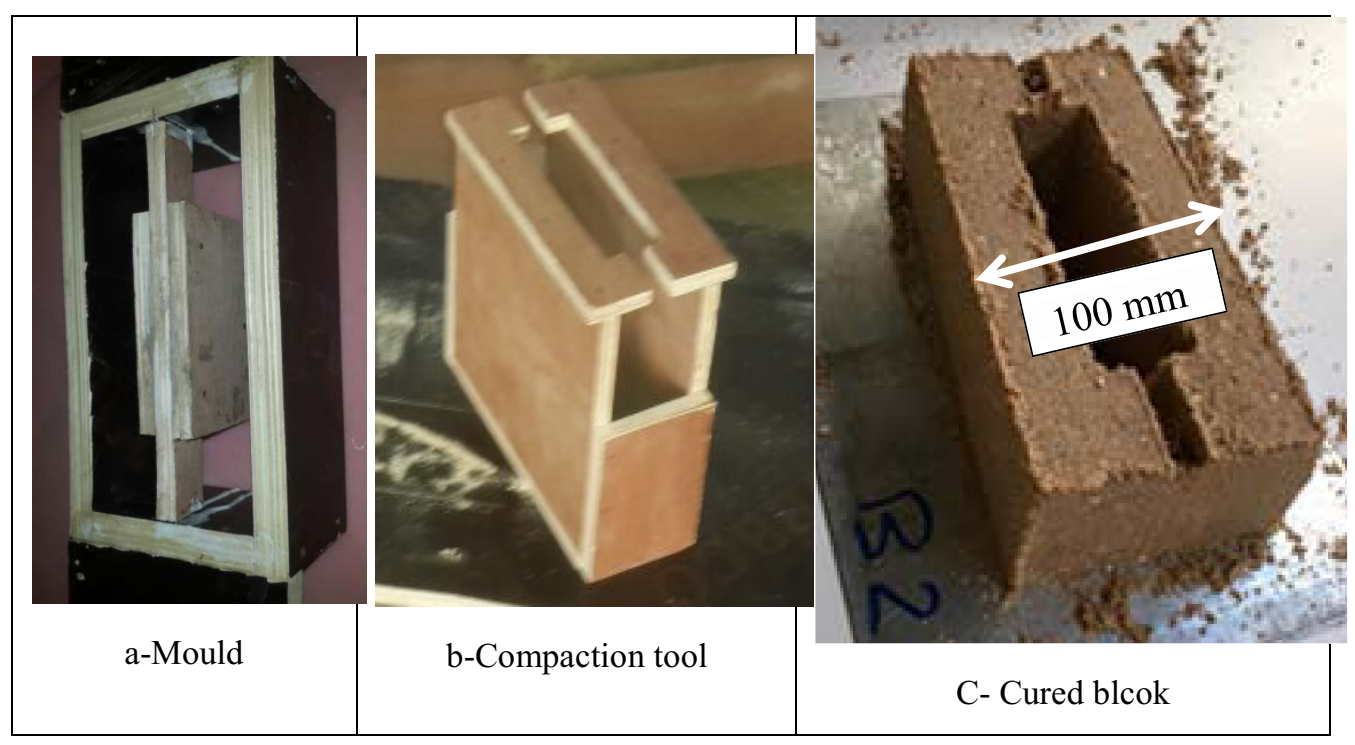

Fig. 7. Mould for Manual block production, and the produced Vegeblock.

\section{Effect of direct flame on vegeblocks}

There was a concern that Vegeblock would catch fire quickly due to the existence of the vegetable oil as a binding agent in the blocks. Initial fire resistance testing was conducted in a third party laboratory in Qatar. The aim of this test was to evaluate the fire hazardous of the Vegeblock, and whether it would catch fire once exposed to direct flame from a gas burner. The building blocks were exposed to a direct flame source two inches away from one face of the sample for two hours. The temperature was measured at the front and back sides of the block using thermocouples. The block was visually investigated before and after the test to evaluate the development of any failures. Fig 8 shows the setup of the experiment a few minutes after the Vegeblocks were exposed to the fire. It was not possible to run this test on the small $50 \mathrm{~mm}$ cubes. The test was conducted on mid-size block samples made of EW and EW+ sand.

The Vegeblock did not catch fire during the test. For Vegeblocks made of EW, a crack appeared after 70 minute. The temperature at the point of cracking had reached $483^{\circ} \mathrm{C}$ on the surface of the VegeBlock and $78.5^{\circ} \mathrm{C}$ on the back side. This was the only time the EW VegeBlock was damaged and thereafter until the 120 minute mark, the block had remained only with that crack. The EW+ sand specimen did not incur any physical damage. The surface colour in both materials changed very quickly.

The temperature profiles of the Vegeblock were recorded and compared to another test results for a conventional concrete hollow block, as presented in Fig 9. The comparison shows that Vegeblock specimens had an initial rapid rise of surface temperature within 30 minutes compared to the linear increase shown by the conventional concrete block, then the Vegeblock's surface temperature increases gradually until about 70 minutes. Over the last 30 minutes of the test, the surface temperature on both VegeBlock specimens increased by only $3-4^{\circ} \mathrm{C}$ every ten minutes. In contrast, the conventional hollow block's surface temperature continued rising in surface temperature at a fast rate throughout the entire two hours reaching $781^{\circ} \mathrm{C}$ whereas the VegeBlock reached $505^{\circ} \mathrm{C}$ in the first 60 minutes and reached a maximum of $528^{\circ} \mathrm{C}$ after 120 minutes. The temperature of the back side for 
Vegeblocks was similar to conventional concrete blocks and the maximum temperature was about $100^{\circ} \mathrm{C}$ at the end of the experiment.

The experiment proved that the oil in the Vegeblock had polymerized to an extent that it is not a fire hazard, and would not catch fire if it is exposed to flame for two hours and for temperature up to $500{ }^{\circ} \mathrm{C}$.

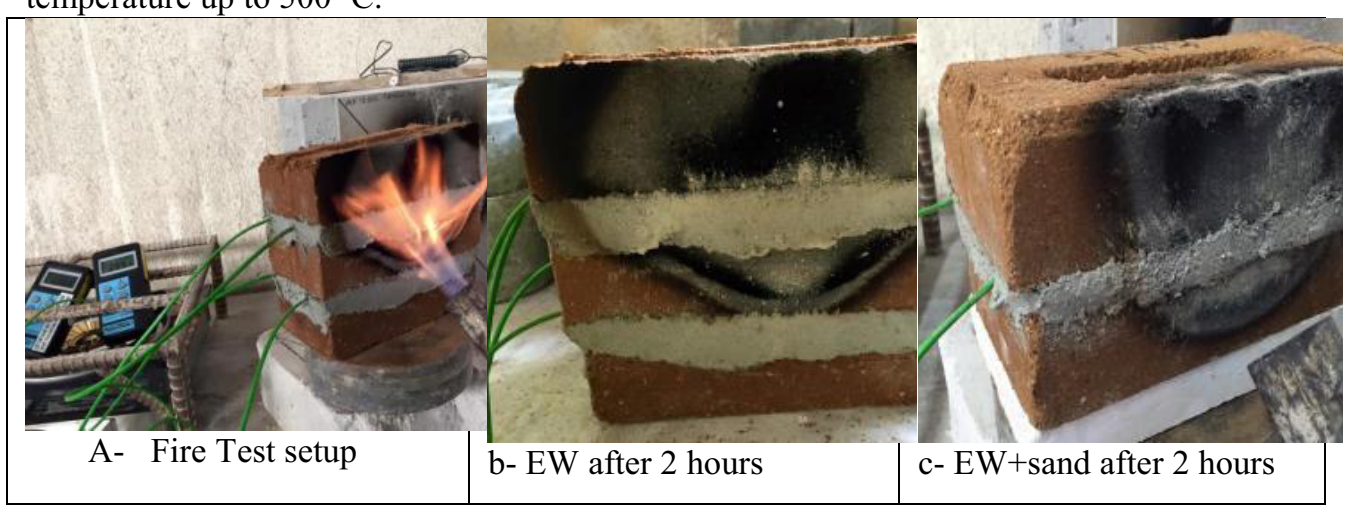

Fig. 8. Fire test setup and samples after the test.

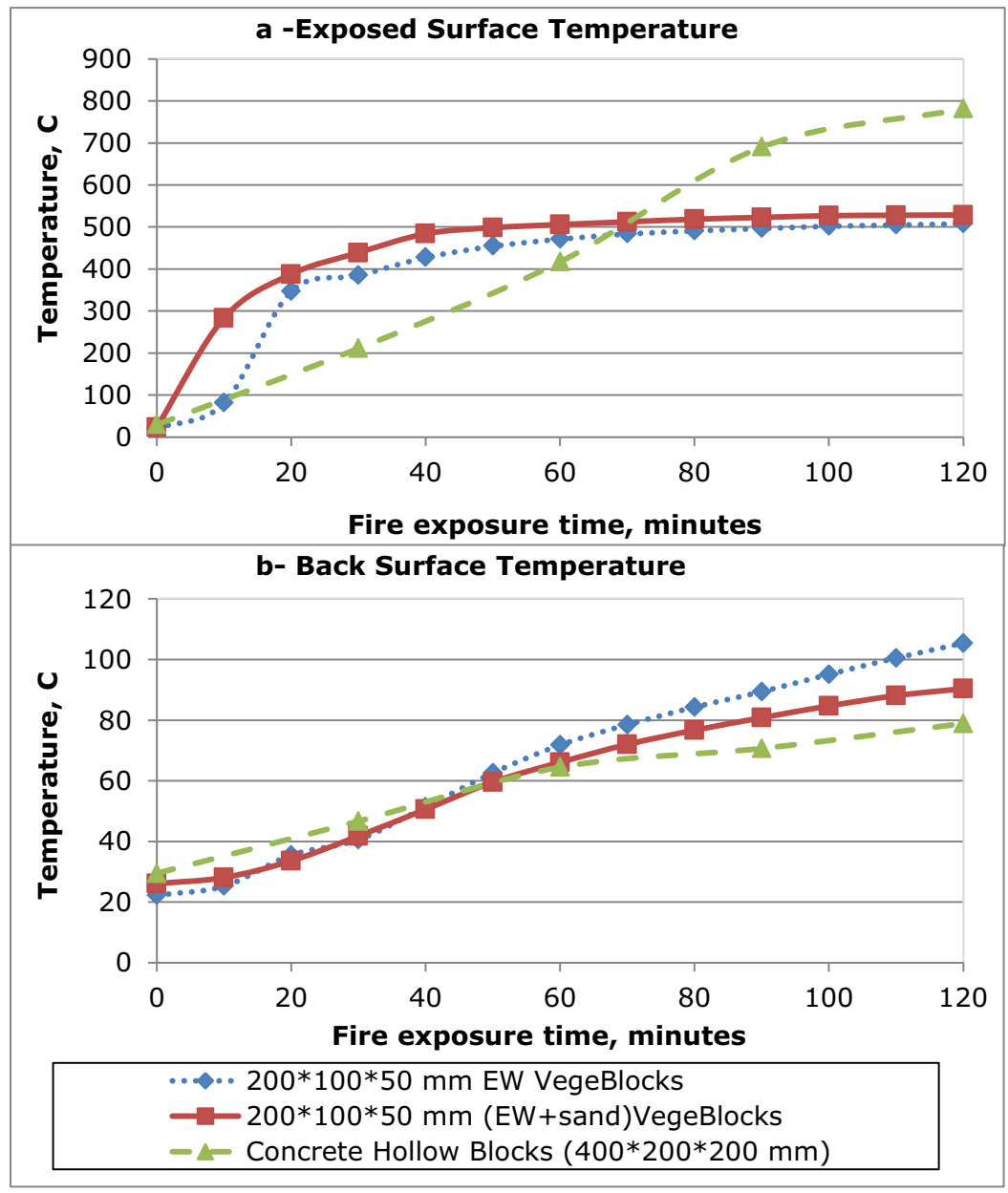

Fig. 9. Temperature profile of tested samples. 


\section{Summary and conclusions}

This paper presented part of the research aimed at evaluating the viability of producing building blocks using recycled aggregate and vegetable oil as a binding agent. Different types of locally available recycled aggregate were evaluated including:

- Limestone excavation waste (EW)

- EW plus incineration bottom ash (IBA) (50/50 by weight)

- EW plus unwashed sand (50/50 by weight)

Two types of oils were used in the production of the Vegeblocks namely:

- Virgin palm oil (VPO)

- Used palm oil (UPO)

The research developed an understanding of the effect of oil content, curing duration and curing temperature on the compressive strength of the Vegeblocks.

Based on the work carried out in the investigation, the following conclusions were made:

- Graded mineral aggregates, when mixed with vegetable oil (virgin or waste) at optimal proportions, then compacted and cured at elevated temperatures can result in blocks (Vegeblock) that have the mechanical characteristics of a conventional building block and can be a viable alternative to concrete blocks.

- Furthermore, the research demonstrated the possibility of producing blocks out of $100 \%$ recycled material (i.e. recycled aggregate and waste oil).

- Excavation waste (EW) and IBA mixtures (which was the weakest material evaluated), achieved the minimum strength required by the QCS 2014 for non-load bearing blocks. Vegeblocks could be a sustainable application for such waste materials.

- For each type of aggregate, there is an optimum oil content (OOC) to achieve the target strength. Increasing the oil content beyond the optimum reduces the strength of the Vegeblocks. The OOC varied from $8 \%$ for $(\mathrm{EW}+$ sand $)$ up to $16 \%$ for blends composed of $(\mathrm{EW}+\mathrm{IBA})$.

- A curing duration of 24 hours gave acceptable levels of strength for Vegeblocks at the optimum oil content. Increasing the curing duration beyond 24 hours improved the strength.

- A high temperature is needed for the Vegeblocks to be adequately cured and to achieve the target strengths. The recommended minimum temperature for curing was found to be $170^{\circ} \mathrm{C}$ and increasing the curing temperature up to $190^{\circ} \mathrm{C}$ resulted in even higher strengths.

- The very delicate and careful operation required to remove and handle the freshly compacted uncured samples is a slight drawback in this process as it may create a challenge when producing samples at full-scale production.

- Mid-size hollow blocks $(200 * 100 * 50 \mathrm{~mm})$ were successfully produced as a step towards full scale production of Vegeblocks.

- The experiment proved that the oil in the Vegeblock had polymerized to an extent that it is not a fire hazard, and would not catch fire if it is exposed to flame for two hours and for temperature up to $500{ }^{\circ} \mathrm{C}$.

The work presented in this paper is part of ongoing research for evaluating and developing a deeper understanding of Vegeblock performance. The Authors are grateful to the Qatar National Research Fund, National Priority Research Program (NPRP 6-1472-2-600) for funding the project. 


\section{References}

1. K.E. Hassan, J.M. Reid and M.S. Al-Kuwari. PPR736, TRL (2015).

2. K.E. Hassan, M.S. Al-Kuwari and J. M. Reid. PEAT, 15, 2 (2014).

3. R. Lutfi. Intern. Pub. Number WO 01/74948 A1. World International Property Organization (2001).

4. J.P. Forth and S. Zoorob. Factor 10 Engineering for Sustainable Cities, IABSE, UK, (2006).

5. S.E. Zoorob, J.P. Forth and H.K. Bailey. Twenty-First Int. Conf. Solid Waste Tech. and Management, USA, 511-520, (2006).

6. J.P. Forth and S. Zoorob. Patent No. US 8,298,330 B2, (2012).

7. T. Heaton, J. Fisher and J.P. Forth. J. of the Am. Oil Chem. Soc., 89, 6, 1101-1111, (2012).

8. J.M. Reid, K.E. Hassan and M. S. Al-Kuwari (2016). Proceedings of the Institution of Civil Engineers - Waste and Resource Management. 169, 1, 21-29, (2016).

9. ASTM D2487. Am. Soc. Testing \& Mat., USA (2011).

10. C. L. Alsberg and A. E. Taylor.

http://journeytoforever.org/biofuel_library/fatsoils/fatsoils1.html, accessed May (2009).

11. ASTM C109/C109M. Am. Soc. Testing \& Mat., USA (2013).

12. QCS, Sec. 13, Part 4, Qatar Standards - Ministry of Environment (2014).

13. State of Qatar. Ministry of Municipal Affairs \& Agric. CML Test Method 9-97 (1997). 